\title{
Wind Analysis of Tall Buildings for Vertical Irregularity : A Review
}

\author{
Syed Mudassir ${ }^{1}$, Dr. Kuldeep Dabhekar ${ }^{2}$, Mohd. Faizuddin ${ }^{3}$, Dr. Isha P. Khedikar ${ }^{4}$
}

Research Scholar Department of Civil Engineering, Nagpur, Maharashtra, India ${ }^{1}$

Assistant Professor, Department of Civil Engineering, G.H. Raisoni College of Engineering, Nagpur, Maharashtra, India ${ }^{2}$

Structural Engineer, Icon Consultants Aurangabad, Maharashtra, India ${ }^{3}$

Assistant Professor Department of Civil Engineering, G.H. Raisoni College of Engineering, Nagpur, Maharashtra, India ${ }^{4}$

\begin{abstract}
Now every day, various buildings are being built for different purposes such as residential, commercial, and industrial etc. In general, in order to stabilize these longitudinal tall structures for both loads such as gravity and lateral (wind and earthquake) loads are required to take when considering the analysis and design. In addition to this there are several types of structures or buildings having different geometry in vertical and horizontal plan in the sense regular or irregular. This paper presents detailed review on the analysis of vertically irregular structure subjected to wind loads, the failure of structure starts from the weak point or joint. This weakness is exacerbated by the uneven distribution of mass, changes in elasticity or stiffness and also changes in the vertical geometry of the structure. Properties that have objections to physical or geometric regularity are referred to as irregular structures. The present study shows a review on analysis and effects in vertical irregular structure under lateral load especially in case of wind load. Many structural software and standard codes are reviewed for the creation of all members under wind load. At the end of this paper concerns the comparison of regular building with irregular structure and describes the effects in vertical irregular structure with the help of structural behaviour such as displacement, drift, axial forces, base shear and bending moment etc.
\end{abstract}

Keywords : Vertical Geometry, Irregularity, Wind Analysis, Stiffness.

\section{INTRODUCTION}

High rise or multi-storey building is part of the urban landscape and is part of the developed world because compacted land promotes high-rise buildings [1]. From the past decades human needs and the change of lifestyle has been increasing day by day more than expected. For example in the 1800s the plan and look of buildings or other structures was very simple and was equivalent to symmetric geometry [2].But now architectural demand arises due to this the plan of buildings becomes asymmetric and irregular in horizontal as well as vertical geometry [3]. This irregularity causes discontinuity in mass and stiffness and geometry of structure. In addition to this height of building also take in consideration at the time of analysis for stability of structure [1]. Now multi-storied buildings or skyscraper are becomes trending. And these two factors namely high rise building and irregularity in geometry gives the task to the structural designer because of collapse and damages on structures starts and increases from the weak point and joints. This weakness is exacerbated by the uneven distribution of mass, changes in elasticity or stiffness 
and also changes in the vertical geometry of the structure. The structures having discontinuity or any objections in physical property or geometry are termed as Irregular structures. There are two types of irregularity namely plan irregularity and vertical geometric irregularity. If Plan having different plan configurations such as L, C, I-Shaped called plan irregularity and in this seismic response is not only translational but also rotational causes eccentricity in mass and stiffness of structure [5]. Vertical irregularity can be defined as when the horizontal dimensions of storey for lateral force resisting system is more than $125 \%$ of its adjacent storey called as Vertical Geometric Irregularity [4]. If the building is located in most sever zone having lateral forces namely wind and seismic then it becomes most critical for stability for structure [18]. At this stage various structural software are used for analyse and design of these structures such as STAAD PRO, ETABS, SAP2000, SAFE etc [15].

\section{EFFECTS OF WIND IN IRREGULAR STRUCTURE}

Vertical irregularity is most vital issue to require in thought during analysis and construction of multistoried building. The behaviour of structures with these irregularities just in case of earthquake and wind force should be study. Multi-storied structures are primarily designed to resist static and dynamic loads [9]. Usually the result of dynamic masses acting on structure isn't taken. This feature of neglecting the dynamic forces generally becomes the reason behind disaster. Over the last 20 years, wind engineering had been genuinely studied and worked on low rise and also high rise buildings. And due to this study it has been seen that the effect of high wind pressure are minimum on low height buildings where as large deformation on high rise buildings [6]. In irregular structure there are uneven separation of mass, stiffness and geometry are present is the property of structure and due this separation or sudden change in geometry causes failure of structure. The vertical irregularity is the main reason of sudden collapse and over turning of structure that's why the irregularity in structure is very essential parameter for structural engineer to take in consideration while designing [7]. A mean wind force acts on a building. This mean wind force comes from the mean wind speed and thus the unsteady wind force created by the unsteady flow field. The results of the unsteady wind force on the building or half therefrom depends not solely on the characteristics of the unsteady wind force however in addition on the size and vibration characteristics of the building. Therefore, so as to analyse wind load it is necessary to know the characteristics and properties of unsteady wind forces and also the dynamic characteristics of the building. The factors which affect the unsteady wind force are: 1) Turbulence of wind (periodic special fluctuation of wind) 2) Vortex generation in building 3) Interaction between encompassing air flow and structure vibration for many buildings, the result of unsteady wind force generated by wind turbulence is most important [10]. Because of this reasons wind load is compulsory to take in consideration in high rise building or the building having the height is more than 10 meters with some factors depending upon type of structure, zone, topography, terrain category, etc [8].

\section{LITRETURE SURVEY}

- A.Pavan Kumar et al. (2017) performed analysis of high rise building about $\mathrm{G}+30$ framed structure building situated in zone four and zone five in soil type 2 (medium soils) and analysis were done by ETABS. Gravity and Lateral loads were considered as per Indian standards with guidelines of IS 1893:2002 for (Earthquake load) and IS 875:1983 for (Wind load). The plan area was taken as $24.14 \mathrm{~m} \times 20.627 \mathrm{~m}$ and height of each storey was $3 \mathrm{~m}$. Modelling and analysis were done in ETABS 2013 software. The results of each zone were 
compared by displacement characteristics, shear at base and storey drift values. And conclude that storey drift is gradually increases from top storey to bottom storey in both zones specially zone 5 has higher value of drift and storey shear. ETABS reduces the time and efforts and gives the all required values in detailed [13].

- Rupesh R.Pawade et al. (2017) Performed (Nonlinear static) pushover analysis on $\mathrm{G}+16$ storied building having vertical irregularity. Five types of buildings are modelled in which one model is regular and other four is vertical irregular. SAP 2000 software is used for analysis and concluded regular building having more capacity to resist lateral forces with minimum deformation as compared to vertical irregular setback buildings [17].

- Shashikanth et al. (2017) shows the demand of vertical irregular structure and need of lateral loads considerations in analysis of tall buildings. Clearly described the weakness in irregular structure which tends to sudden failure or rupture caused by uneven separation in mass, change in stiffness and vertical geometry of structure. Described difference in regular and irregular structure according to analysis. Also defined the termed 'irregularity' with its two types namely Plan irregularity and Vertical irregularity. Vertical irregularity is said to be when in a storey the horizontal area of wind force resisting surface is $150 \%$ more than its adjacent storey. Three models were prepared for analysis. In which one model is regular (same geometry till top storey i.e. $15^{\text {th }}$ storey) and other two was irregular having setbacks at different levels (one sided vertical setback at $4^{\text {th }}$ storey and $8^{\text {th }}$ storey respectively) and two sided vertical setbacks at $4^{\text {th }}$ storey. All models having 900 meter square area and $45 \mathrm{~m}$ height each. ETABS was used for modelling and analysis of all structure. All loads taken as per Indian code. For wind load IS 875-1987 were used. And compared the results of all models with roof displacement, storey drift and base shear. And at the end conclude that i) irregular geometric structure poses same base shear but gives higher value of inter storey drift values. ii) In case of irregular structure having setbacks at lower level shows the maximum displacement values as compared to other irregular structure having setbacks at high level. iii) Regular Structure without setbacks proved safest structure with little amount of displacement value [4].

- K.divya et al. (2016) explained the types of structure with respect to regular structure and irregular structure and effects of wind force of $50 \mathrm{~m} / \mathrm{sec}$ on tall structures such as it exerts lateral forces and moments in structure. This paper is depend upon Indian standard codes and followed IS 875 part 3-1987 for wind load. In these paper four models $(\mathrm{G}+10)$ was prepared having total height of $37.5 \mathrm{~m}$ with the plan area of $35.77 \mathrm{~m} \mathrm{x}$ $24.42 \mathrm{~m}$. Four models was prepared for different irregularity the models are Regular, vertical irregular, stiffness irregular and vertical and stiffness irregular buildings. Showed the detailed calculations of gravity and lateral load. Analysis was done by using Staad pro software. At the end conclude that bending moments and shear forces gives minimum values with its increasing height in regular and stiffness irregular buildings. Models having irregularities shows maximum amount of displacement and deformation as compared to regular building [12].

- N.Anvesh et al. (2015) Wind engineering has more focused over last two decades on high rise as well as modest height buildings. Worked on analysis of G+10 storied building under lateral loads and compared regular building with mass irregular building having same configuration but change in load in $3^{\text {rd }}$ and $6^{\text {th }}$ storey (mass irregular). Shows 
effect on structure due to mass irregularity. E-tabs software is used for analysis and resulted that in refuse area beam gives more value of bending moment and shear force with $67 \%$ more in mass irregular building. Displacement and sizes of structural members increases in mass irregular building [6].

- Anju Krishna et al. (2015) the architectural demand arises and it becomes necessary to take lateral loads consideration in tall buildings. Explained lateral forces resisting systems in structure such as shear wall, rigid frame wall frame, braced tube system, and diagrid system. The diagrid resisting system is mostly use in tall buildings because of its great lateral load resisting efficiency and architectural appearance. The diagonal members as a beam are used in this system with the angle of inclination 74.5 degree. In this study 36 storied building is modelled having $130 \mathrm{~m}$ height with plan area of $36 \mathrm{~m} \times 36 \mathrm{~m}$. Three models were prepared having vertical irregularity with the setbacks at $25 \% 50 \% 75 \%$ total height of building. Steel sections were used as members of diagrid and columns of structure. Same ideal models were prepared in tubular system and compared with diagrid system structure. All gravitational as well as lateral loads are taken from Indian standard codes. Wind speed was taken as $30 \mathrm{~m} / \mathrm{sec}$. After analysis of all models conclude that the diagrid system having vertical irregularity shows little amount of displacement and storey drift value as compared to tubular system. Diagrid system gives more attractive architectural appearance and better interior space as compared to conventional systems. Diagrid system proved more efficient system in high-rise building with vertical irregularity under maximum wind loads [11].

- Md. Mahmud et al. (2015) has worked on has worked on building shapes and elaborates the effects on each shape under wind and earthquake.
And presents the numerical study of various effects on different shapes of buildings subjected to lateral loads. Three different complex shaped buildings are taken and compared with each other under critical wind and earthquake loads. Designing procedure is done by using (BNBC) 2006 that is standard national code from Bangladesh. Shows the effects on different building shapes through displacement of building by considering L-Shaped, hollow rectangle shaped and rectangle with more corners having ideal plan area of 600 sq.m and $18 \mathrm{~m}$ height. In (BNBC) having several methods to analyse the lateral forces. There are two highlighted and more convenient methods are available to analyse the wind forces namely 'surface area method' and 'projected area method'. In this study 'projected area method, were used because it is applicable for all types of structure and it is more relevant method by considering wind pressure to overall vertical projected area. And for seismic analysis 'Equivalent static force' method is used. Results are compared on the basis of storey drift, base shear and nodal displacement and conclude that maximum displacement is occur due to wind pressure in L-shaped building in axis having small area because the system of resisting wind pressure is depend upon wind contact surface area. The weakest node in case of earthquake load is not weak for wind load. Also maximum storey drift have been seen in the same model [2].

- Abhay guleria (2014) Describe the advantages of ETABS software using for analysis of multi storey and different plan configuration buildings. Shows the structural behavior of multi storied structure with rectangular, L, I and C-shaped plan buildings. The 15 storied building were considered in each case and after analysis of all cases are compared with each other for individual structural behaviour in terms of maximum shear force, bending moment and storey displacement. The plan area of 
$32 \mathrm{~m} \times 24 \mathrm{~m}$ considered with each storey height of $3 \mathrm{~m}$. Buildings are situated in zone 5 . All loads are taken from Indian standard codes. Modelling was done by ETABS because of its simplicity and accuracy. And conclude that L-shaped and Ishaped plan structure shows the nearly same in result. Asymmetric plans undergo more deformations hence symmetrical plan should be adopted [3].

- Ramesh Konakalla (2014) Shows impact of vertical irregularity in multi storied buildings when dynamic loading is subjected. In this linear static analysis considering four forms of 20- Storied 3D frames. Found for regular frame, there's no torsional impact within the frame within the symmetry. The response for vertically irregular buildings is totally different for the columns that are situated within the plane perpendicular to the action of force. This is often because of the torsional rotation within the structure [16].

- Sarkar et al. (2010) had worked on stepped building frames having vertical irregularity. Shows the example of stepped building in Delhi India. Proposed alternative process for estimating the irregularity present in building frames to know well about dynamic characteristics of the same building such as mass of structure and stiffness also proposed the equation to determine the fundamental time period for irregular stepped buildings. This formula is valid for all types of stepped buildings having vertical irregularity [14].

\section{CONCLUSION}

In this study many papers are reviewed and now aware with irregularity of structure there are two types of irregularity such as plan irregularity and vertical irregularity. And vertical irregularity create weakness in structure and leads to its failure due to separation in mass, stiffness when it is under lateral loads (wind and seismic). But in case of multi-storied building the wind analysis are most critical as compare to seismic. Many standard codes are available for different countries. To assign the wind loads many of researchers used ETABS structural software. It gives the analytical results and behaviour of structure with less effort. From this study it is observed that the value of drift is increases from top storey to bottom storey with sudden fluctuation at irregular floor. Obtained the higher values of drift, axial force, bending moment and base shear in case of vertical irregular structure subjected to lateral loads. In the irregular structure observed the higher amount of joint displacement for lateral loads as compared with regular structure. ETABS reduces the effort and time and easily operating software used for analysis especially for lateral loads and details of each and every member can be obtained. The vertical irregular structures needs Morden and effective lateral forces resisting system such as tubular system and diagrid system.

\section{REFERENCES}

[1]. S.M.N.H.Koliyabandara1*,H.M.A.D.Jayasundara2, K.K.Wijesundara3 "ANALYSIS OF WIND LOADS ON AN IRREGULAR SHAPED TALL BUILDING USING NUMERICAL SIMULATION" ICSECM2017-456

[2]. MD. MAHMUD SAZZAD, MD. SAMDANI AZAD "Effect of building shape on the response to wind and earthquake" ISSN 2319-5347, Vol. 04, No. 04, October 2015

[3]. Abhay Guleria "Structural Analysis of a MultiStoreyed Building using ETABS for different Plan Configurations" ISSN :2278-0181 Vol. 3 Issue 5, May - 2014

[4]. SHASHIKNATH H, ${ }^{2}$ SANJITH J, ${ }^{3} \mathrm{~N}$ DARSHAN: "ANALYSIS OF VERTICAL GEOMETRIC IRREGULARITY IN RC STRUCTURE SUBJECTEDTO WIND LOAD” ISSN: 2455-2631 September 2017 IJSDR | Volume 2, Issue 9 
[5]. Pardeshi sameer, Prof. N. G. Gore (2016) "Study of seismic analysis and design of multi storey symmetrical and asymmetrical building" International Research Journal of Engineering and Technology (IRJET) e-ISSN: 2395 -0056 Volume: 03 Issue: 01, Jan-2016.

[6]. N.Anvesh 1, Dr. Shaik Yajdani2, K. Pavan kumar "Effect of Mass Irregularity on Reinforced Concrete Structure Using Etabs" Vol. 4, Issue 10, October 2015, ISSN(Online):2319-8753

[7]. Piyush Mandloi, Prof. Rajesh Chaturvedi “ Seismic Analysis of Vertical Irregular Building with Time History Analysis" Volume 14, Issue 4 Ver. III (Jul. - Aug. 2017) e-ISSN: 2278-1684,p-ISSN: 2320$334 \mathrm{X}$

[8]. IS 875(Part III):1987, Codes Of Practice For Design Loads Other Than Earthquake) For Buildings And Structures - Wind Loads Bureau Of Indian Standards

[9]. Salar Manie(2014) "Collapse safety assessment of low rise building with mass irregularities in plan." by Tenth U.S. National Conference on Earthquake Engineering, Alaska.

[10]. B. S. Mashalkar 1 , G. R. Patil 2 , A.S.Jadhav.3 "Effect of Plan Shapes on the Response of Buildings Subjected To Wind Vibrations" e-ISSN : 22781684, p-ISSN : 2320-334X

[11]. Anju Krishna1, Arathi S2, "Analytical Study of Vertical Geometric Irregular Diagrid Structure and Comparison with Tubular Structure" (2015) ISSN (Online): 2319-7064

[12]. K.divya S.sai harsha "COMPARITIVE STUDY ON STURUCTURES HAVING VERTICAL AND STIFFNESS IRREGULARITIES UNDER WIND LOAD” Volume: 03 Issue: 08 | Aug-2016 e-ISSN: $2395-0056$

[13]. A.Pavan Kumar Reddy1, R.Master Praveen Kumar2 "Analysis of G+30 Highrise Buildings by Using Etabs for Various Frame Sections In Zone IV and Zone V" ISSN(Online): 2319-8753 ISSN (Print): 2347-6710 Vol. 6, Issue 7, July 2017

[14]. Sarkar P, Prasad A Meher, MenonDevdas, 2010, "Vertical geometric irregularity in stepped building frames" Engineering Structures 32 (2010) 21752182

[15]. Salahuddin Hammad, Habib Saqib, Rehman Talha , "Comparison of design of a building using ETABS V 9.5 \& STAAD PRO” 2005

[16]. Ramesh Konakalla "effect of vertical irregularity in multi storied buildings under dynamic loading using linear static analysis" (2014) ISSN: 2348-0033

[17]. Rupesh R. Pawade1, Dr.M.N.Mangulkar2 "Influence of Combine Vertical Irregularities in the Response of Earthquake Resistance Rc Structure" e-ISSN: 2278-1684,p-ISSN: 2320-334X, Volume 14, Issue 1 Ver. IV (Jan. - Feb. 2017), PP 33-40

[18]. Nabiollah Alirahimi Kashkooli and MahmoudReza Banan "Effect of Frame Irregularity on Accuracy of Modal Equivalent Nonlinear Static Seismic Analysis" KSCE Journal of Civil Engineering (2013) 17(5):1064-1072

Cite this article as : Syed Mudassir, Dr. Kuldeep Dabhekar, Syed Faiz, Dr. Isha P. Khedikar, "Wind Analysis of Tall Buildings for Vertical Irregularity : A Review ", International Journal of Scientific Research in Science and Technology (IJSRST), Online ISSN : 2395-602X, Print ISSN : 2395-6011, Volume 7 Issue 3, pp. 121-126, May-June 2020. Available at doi : https://doi.org/10.32628/IJSRST196624 Journal URL : http://ijsrst.com/IJSRST196624 